\title{
Associations of the Neighborhood Environment With Substance Use: A Cross-sectional Investigation Among Patients in Compulsory Drug Detention Centers in Thailand
}

\author{
Suneerat Yangyuen', Manop Kanato', Udomsak Mahaweerawat ${ }^{2}$ \\ ${ }^{1}$ Faculty of Medicine, Khon Kaen University, Khon Kaen, Thailand; ${ }^{2}$ Faculty of Public Health, Mahasarakham University, Mahasarakham, Thailand
}

Objectives: To identify the associations of characteristics of the neighborhood environment with substance abuse among clients receiving treatment for drug abuse in Thailand.

Methods: A cross-sectional study was conducted of 1128 drug addicts from 28 neighborhoods who were receiving treatment at all 7 compulsory drug detention centers in Thailand. A trained interviewer conducted structured interviews with the subjects about substance use and the perceived neighborhood environment in their community. A multilevel logistic regression model was applied to estimate the effects of the neighborhood environment on substance use.

Results: The majority of participants, $53.8 \%$ only used methamphetamine pills, $31.3 \%$ used other illicit drugs as well as methamphetamine pills, and $14.9 \%$ used an illicit drug other than methamphetamine. Three neighborhood characteristics were associated with substance use. A 1-unit increase in the perceived neighborhood cohesion score was associated with a 15\% reduction in methamphetamine pill use and an 11\% reduction of the use of both methamphetamine pills and another illicit drug. Conversely, a 1-unit increase in perceived neighborhood crime predicted 19 and 14\% increases in the use of methamphetamine pills and the use of both methamphetamine pills and another illicit drug, respectively. In addition, a 1-unit increase in the scores for stigma surrounding addiction corresponded to a $25 \%$ increase of the use of methamphetamine pills and a $12 \%$ increase in the use of both methamphetamine pills and another illicit drug.

Conclusions: Substance use among drug addicts was influenced by characteristics of the neighborhood environment. Therefore, prevention and intervention strategies should be designed based on a consideration of the impact of neighborhood context on substance use behaviors.

Key words: Neighborhood, Substance abuse, Association, Thailand

Received: September 8, 2017 Accepted: December 7, 2017

Corresponding author: Manop Kanato, PhD

Faculty of Medicine, Khon Kaen University, 123 Mitaparb Road,

Mueang District, Khon Kaen 40002, Thailand

E-mail: manopkanato@gmail.com

This is an Open Access article distributed under the terms of the Creative Commons Attribution Non-Commercial License (http://creativecommons.org/licenses/by-nc/ 4.0//) which permits unrestricted non-commercial use, distribution, and reproduction in any medium, provided the original work is properly cited.

\section{INTRODUCTION}

Substance use remains a significant problem worldwide. Since 2014, the United Nations Office for Drugs and Crime was estimated for total 247 million people used drug, and onesixth of the world's drug users have received treatment [1]. In the last decade, a substance use epidemic has led to the implementation of compulsory treatment systems in many East 
and Southeast Asian countries, such as China, Vietnam, Cambodia, Malaysia, Laos, and Thailand [2]. In such programs, people who use drugs (PWUD) or who are suspected of drug use are arrested by police, and then receive treatment and rehabilitation in compulsory drug detention centers (CDDCs). It has been estimated that more than 235000 PWUD have been detained in over 1000 centers in several Asian countries. Meanwhile, CDDCs in Southeast Asian countries have been found to be ineffective, and some PWUD have suffered from physical and psychological harms, such as human immunodeficiency virus (HIV) infection, human rights abuses, and high relapse rates [3].

The first implementation of CDDCs in Thailand was an intervention targeting the methamphetamine epidemic through bureaucratic legal means; in this reform, PWUD were classified as patients, instead of criminals [4]. From 2010 to 2014, the number of PWUD treated in CDDCs increased from 119250 to 179331 cases, and approximately $90 \%$ of these PWUD were methamphetamine users [5]. However, CDDCs have a high relapse rate, which may take place because detainees are released to their neighborhoods, which may have factors predisposing them to return to a cycle of drug abuse, such as high unemployment rates, low socioeconomic status, high crime rates, a greater availability of drugs, and the presence of drug users [6-9]. Thomson [10] and Kallanasute et al. [11] found that about 20 and $14.9 \%$ of subjects relapsed within 2-6 months, respectively. Therefore, CDDCs should both promote abstention from drug use for a short period and urge clients to refrain from engaging with environmental factors in the neighborhood that might influence them to relapse.

Several studies have found substance use behavior to be affected by multiple social determinants, including personal characteristics and multifactorial relationships within the neighborhood $[6,12,13]$. Nevertheless, some traditional studies have focused on individual and interpersonal factors, rather than social and contextual factors on the neighborhood level $[12,14]$. Some recent studies have explored the degree to which negative neighborhood-level factors influence the risk of relapse (e.g., violence, crime, and neighborhood disorderliness) $[15,16]$, some have focused on positive neighborhood factors (e.g., neighborhood cohesion, social capital, and neighborhood safety), and a few studies have considered both sets of factors simultaneously [12,17].

Contemporary studies have documented both positive neighborhood environmental factors (e.g., neighborhood co- hesion is an element of social capital that reflects social ties and networks and neighbors' willingness to intervene for the common good [18]) and negative factors (e.g., neighborhood crime and stigma surrounding addiction). Patterson et al. [17] and Mennis et al. [19] reported that neighborhoods with high social cohesion may influence both the behavioral health and psychological reactions of residents, including a protective function against drug use. In contrast, prior studies of neighborhood crime have shown that neighborhoods with social disorganization (including crime, violence, and drug dealing) may have higher levels of substance use, leading to stress and high rates of crime and perceived crime.

Thus, for those who reside in more disorganized neighborhoods, crime can lead to stress, and drugs may be used to reduce stress $[15,20]$. In terms of the stigma surrounding addiction, Tomori et al. [9] and Livingston et al. [21] reported that after rehabilitation, individuals may return to their community, in which stigmatized attitudes remain present, and be labeled as people who engage in substance abuse, and the resulting sense of hopelessness and social condemnation may put them at risk of relapsing.

In Thailand, previous studies investigating how social factors influence substance use focused on a combination of individual, peer, and family factors, rather than on the neighborhood environment [7,22]. In another study, perceptions of neighborhood cohesion were associated with adolescent delinquency, but no strong significant association was found with substance use [23]. Associations of neighborhood environmental characteristics with substance use among adults and drug offenders have not been conducted in sufficient depth for analyses of both negative and positive neighborhood factors to be analyzed in the same study. This gap in the literature should be addressed.

This study aimed to investigate the association between neighborhood-level environmental factors and substance use among drug addicts in CDDCs through socio ecological model simulation following the method described by Bronfenbrenner [24], with a focus on the interplay among individual, interpersonal, and community variables. Three neighborhoodlevel variables (perceptions of neighborhood cohesion, neighborhood crime, and stigma surrounding addiction) were the primary exposures of interest among both individual-level and interpersonal-level variables, with appropriate adjustment for covariates. We hypothesized that substance use would be influenced by individual and interpersonal characteristics as 
represented by neighborhood factors, and we expect our findings to be helpful for developing intervention strategies to reduce substance use among drug offenders based on a consideration of neighborhood dynamics in their communities.

\section{METHODS}

\section{Study Population and Data Collection}

This cross-sectional study was conducted from December 2015 to July 2017 in all 7 CDDCs located in central (Patum Thani), southern (Songkha, Pattani), northeastern (Khonkaen, Udon Thani), and northern (Chiangmai and Maehongson Provinces) Thailand, which are operated by the Ministry of Public Health of Thailand. The eligible PWUD were enrolled in treatment throughout the study period, resided in the province where the CDDC in which they were detained was located for at least 3 months, and were willing to participate. Participants were excluded if they provided incomplete responses. A consecutive sampling technique was used to select participants who met the eligibility criteria. All 1128 PWUD who met all criteria, which satisfied the calculation of the sample size required for this study. All subjects were divided into 28 neighborhood clusters by the administrative unit of municipalities in each province. This study received ethical approval from the Research Ethics Boards of Khon Kaen University and the Princess Mother National Institute on Drug Abuse Treatment (ref no. HE581318).

We simulated a socio ecological model, in which a multi-level framework is used to understand the multi-faceted interactions between individuals and environmental factors that shape their behavior [24]. Data were collected by structured interviews administered by 14 standardized interviewers at the 7 CDDCs. All respondents provided written informed consent, and were then interviewed in a private room.

\section{Measurement}

The structured interview questionnaire was composed of 4 parts, corresponding to individual-level, interpersonal-level, and neighborhood-level variables, as well as substance use.

\section{Covariates}

The individual-level variables included age, sex, education, occupational status, monthly income, drug-related crime history, and having experienced human rights abuses. All variables were categorized as dichotomous variables, except for the monthly income variable, which was categorized into tertiles.

The interpersonal-level variables were assessed by 2 items reflecting the extent to which peers and family members used methamphetamine, cannabis, or other illicit drugs (OIDs). Potential covariates were accounted for by adjusting for individual- and interpersonal-level variables. These variables were selected based on evidence regarding factors that affect substance abuse and the neighborhood environment identified in the literature reviews of Rodriguez et al. [6], Tomori et al. [9], Galea et al. [12], Embry et al. [14], Theall et al. [16], Mennis et al. [19], Cheng et al. [22], and Silins et al. [25].

Neighborhood-level variables were assessed based on the 3 months prior to detention, Perceptions of neighborhood cohesion were assessed by a scale adapted by Sampson et al. [18] and Buckner [26] reflecting social ties, networks, and trust among residents. This scale comprised 18 items and used a 4-point scale, ranging from "strongly disagree" (1) to "strongly agree" (4). We estimated neighborhood-level cohesion scores by calculating the mean of an individual's total scores for each neighborhood, with higher mean scores indicating a greater perception of neighborhood cohesion (Cronbach alpha, 0.94); Perceptions of neighborhood crime were measured by a questionnaire adapted by Rosenberg et al. [27] and Martinez et al. [28], including 2 items: concerns about crime and neighborhood crime problems. The responses for concerns about crime ranged from 1 (strongly disagree) to 4 (strongly agree) on a 4-point scale, while those for neighborhood crime problems ranged from 1 (rarely/not worried) to 10 (frequently/very). To estimate the neighborhood-level crime score, the mean of the individual's total scores was calculated for each neighborhood, with higher mean scores representing high perceived neighborhood crime (Cronbach alpha, 0.88); Stigma surrounding addiction was assessed using a scale developed by Kanato and Leyatikul [29]. This summed rating scale comprised 30 items with the 5 dimensions of familiarity, perceptions of dangerousness, fear, social distance, and community responsiveness. Neighborhood-level addiction stigma scores were calculated by the mean of the individual's total scores for each neighborhood, with higher mean scores indicating a greater level of stigma surrounding addiction (Cronbach alpha, 0.84).

\section{Outcome variable}

The primary outcome was illicit substance use. The respondents were asked whether they had used any of the following 
10 illicit substances in the last 3 months: methamphetamine pills, crystal methamphetamine, cannabis, inhalants, heroin, cocaine, kratom (Mitragyna species), ecstasy, ketamine, and opioids. Substance use was then divided into the following 3 categories: methamphetamine pill use only (MET-AMP), OID with MET-AMP, and OID without MET-AMP.

\section{Data Analysis}

Descriptive statistics were applied to analyze all socioecological factors. Next, a 2-level multilevel multinomial logistic regression analysis via generalized linear mixed models was fitted to analyze the strength of the associations among neighborhood-level variables, each covariate, and substance use. The 2-level structure comprised individuals at level 1 (including individual-level and interpersonal-level variables) nested within neighborhoods at level 2 (consisting of 3 neighborhood variables). The model building process started with a null model consisting of no predictors, and a series of 2-level models was developed. First, in model 1, we fitted only individual-level variables into the model. Then, in model 2 , all interpersonal-level variables were entered into model 1. Finally, in model 3, all neighborhood-level variables were entered into model 2. In all models, the reference group of the outcome variable was OID without MET-AMP. The median odds ratio (mOR) and interval odds ratio (IOR) was applied for measure the variation of substance use in different neighborhoods and effects of neighborhood-level variables, respectively. The level of statistical significance was set as $p$-value $<0.05$, and SPSS version 20.0 (IBM Corp., Armonk, NY, USA) was used to conduct all statistical analyses.

\section{RESULTS}

\section{Description of Sample Characteristics}

Almost all subjects (85.4\%) were male, and their average age was 27.3 years old (standard deviation, 9.04 years). About half (51.7\%) of the PWUD had completed primary school or less, $74.7 \%$ were employed, and $74.4 \%$ had a drug-related crime history. Most respondents stated that their friends (71.3\%) and family (55.6\%) used drugs. In terms of the substance(s) used, MET-AMP (53.8\%) was the most common, followed by OID with MET-AMP (31.3\%) and OID without METAMP (14.9\%) (Table 1).

\section{Bivariate Models}

In both the MET-AMP category and the OID with MET-AMP category, perceived neighborhood cohesion was significantly associated with decreased substance use. Conversely, perceived neighborhood crime and stigma surrounding addiction were significantly related with increased substance use. Respondents who had completed primary school or less tended to have a history of drug-related crime, and those whose peers used drugs were more likely to use MET-AMP and OID with MET-AMP than to use OID without MET-AMP (Tables 2 and 3).

\section{Multilevel Models}

The $\mathrm{mOR}$ in all models was greater than 1 , indicating that the between-neighborhood variation in substance use was greater than the neighborhood-level variation; all of the IOR$80 \%$ intervals contained 1 , further confirming this finding (Tables 2 and 3 ).

Table 2 presents the results of the multilevel multinomial logistic regression models for MET-AMP. In model 1, the analysis of the relationships of the individual-level variables with substance use showed that a higher likelihood of MET-AMP use was associated with male sex, a younger age, having completed primary school or less, and having a history of drug-related crime. In model 2, drug use by peers and family members was associated with an increased likelihood of MET-AMP. In the final model (model 3), 3 neighborhood-level variables were added into the model, and the results were almost identical to those of model 2. In addition, each 1-unit score increase in perceived neighborhood cohesion was associated with a significantly reduced odds ratio of MET-AMP (15\%). In contrast, 1-unit increments in the scores for perceived neighborhood crime and the stigma surrounding addiction corresponded to a 19 and 25\% increase in the likelihood of MET-AMP, respectively.

Multiple-drug users used OID with MET-AMP. A series of similar models was used to estimate the odds of OID with MET-AMP, as shown in Table 3. In models 1 and 2 of this category, older respondents were less likely to use OID with METAMP than were younger respondents. Completing primary school or less, unemployment, a history of drug-related crime, and reporting drug use by peers and family were significantly related to an increase in the likelihood of OID with MET-AMP. Finally, in model 3, the results showed similar associations of individual-level and interpersonal-level variables with sub- 
Table 1. Distribution of individual, interpersonal, and neighborhood-level independent variables by substance use

\begin{tabular}{|c|c|c|c|c|}
\hline & $\begin{array}{c}\text { Total } \\
(\mathbf{n}=1128)\end{array}$ & $\begin{array}{c}\text { MET-AMP } \\
(\mathrm{n}=607)\end{array}$ & $\begin{array}{l}\text { OID with MET-AMP } \\
\qquad(\mathrm{n}=353)\end{array}$ & $\begin{array}{l}\text { OID without MET-AMP } \\
\qquad(n=168)\end{array}$ \\
\hline \multicolumn{5}{|l|}{ Individual level } \\
\hline \multicolumn{5}{|l|}{ Sex } \\
\hline Male & $963(85.4)$ & $543(89.5)$ & 276 (78.2) & $144(85.7)$ \\
\hline Female & $165(14.6)$ & $64(10.5)$ & $77(21.8)$ & $24(14.3)$ \\
\hline \multicolumn{5}{|l|}{ Age (y) } \\
\hline$\geq 18$ & $963(85.4)$ & $537(88.5)$ & $280(79.3)$ & $146(86.9)$ \\
\hline$<18$ & $165(14.6)$ & $70(11.5)$ & $73(20.7)$ & $22(13.1)$ \\
\hline \multicolumn{5}{|l|}{ Monthly income (THB) } \\
\hline$<5000$ & 448 (39.7) & $226(37.2)$ & $152(43.2)$ & $70(41.7)$ \\
\hline $5000-8000$ & $353(31.3)$ & 201 (33.2) & $103(29.2)$ & $49(29.2)$ \\
\hline$>8000$ & $327(29.0)$ & $180(29.7)$ & $98(27.8)$ & 49 ()29.2 \\
\hline \multicolumn{5}{|l|}{ Education } \\
\hline Primary school or lower & $583(51.7)$ & $322(53.0)$ & $188(53.3)$ & $73(43.5)$ \\
\hline Secondary school or above & $545(48.3)$ & $285(47.0)$ & $165(46.7)$ & $95(56.5)$ \\
\hline \multicolumn{5}{|l|}{ Occupational status } \\
\hline Unemployed & $285(25.3)$ & $145(23.9)$ & $103(29.2)$ & $37(22.0)$ \\
\hline Employed & $843(74.7)$ & $462(76.1)$ & $250(70.8)$ & $131(78.0)$ \\
\hline \multicolumn{5}{|l|}{ Drug-related crime history } \\
\hline Yes & $839(74.4)$ & $458(75.5)$ & $270(76.5)$ & $111(66.1)$ \\
\hline No & $289(25.6)$ & $149(24.5)$ & $83(23.5)$ & $57(33.9)$ \\
\hline \multicolumn{5}{|l|}{ Human rights violation } \\
\hline Yes & $143(12.7)$ & 75 (12.4) & $50(14.2)$ & $18(10.7)$ \\
\hline No & 985 (87.3) & $532(87.6)$ & 303 (85.8) & $150(89.3)$ \\
\hline \multicolumn{5}{|l|}{ Interpersonal level } \\
\hline \multicolumn{5}{|l|}{ Family substance use } \\
\hline Yes & $627(55.6)$ & $360(59.3)$ & $187(53.0)$ & $80(47.6)$ \\
\hline No & $501(44.4)$ & $247(40.7)$ & $166(47.0)$ & $88(52.4)$ \\
\hline \multicolumn{5}{|l|}{ Peer substance use } \\
\hline Yes & 804 (71.3) & $453(74.6)$ & $254(72.0)$ & $97(57.7)$ \\
\hline No & $324(28.7)$ & $154(25.4)$ & $99(28.0)$ & $71(42.3)$ \\
\hline \multicolumn{5}{|l|}{ Neighborhood level } \\
\hline Perception of neighborhood cohesion & $61.8 \pm 5.8$ & $60.1 \pm 6.1$ & $62.6 \pm 5.2$ & $66.1 \pm 2.8$ \\
\hline Perception of neighborhood crime & $70.3 \pm 6.4$ & $72.5 \pm 6.6$ & $69.2 \pm 4.7$ & $64.6 \pm 4.4$ \\
\hline Stigma surrounding addiction & $82.7 \pm 5.6$ & $84.9 \pm 5.8$ & $81.2 \pm 4.2$ & $77.9 \pm 2.8$ \\
\hline
\end{tabular}

Values are presented as number (\%) or mean \pm standard deviation.

MET-AMP, methamphetamine pill use only; OID, other illicit drugs; THB, Thai baht.

stance use as in model 2. Moreover, as was the case for the MET-AMP category, each 1-unit increase in perceived neighborhood cohesion scores decreased the likelihood of OID with MET-AMP by $11 \%$. In contrast, every 1 -unit increase in the scores for perceived neighborhood crime and the stigma surrounding addiction increased the odds of OID with MET-AMP by 14 and $12 \%$, respectively.

\section{DISCUSSION}

The results showed that greater perceived neighborhood cohesion was associated with a decrease in both MET-AMP and OID with MET-AMP, compared to OID without MET-AMP, in accordance with the findings of Duncan et al. [13], Patterson et al. [17], and Lin et al. [30]. A possible explanation for this finding is that neighborhoods with high cohesion influence 
Table 2. ORs and 95\% Cls from the multilevel multinomial logistic regression for methamphetamine pill use only

\begin{tabular}{|c|c|c|c|c|}
\hline & $\begin{array}{c}\text { Bivariate } \\
\text { OR (95\% CI) }\end{array}$ & $\begin{array}{c}\text { Model } 1 \\
\text { aOR (95\% CI) }\end{array}$ & $\begin{array}{c}\text { Model } 2 \\
\text { aOR (95\% CI) }\end{array}$ & $\begin{array}{c}\text { Model } 3 \\
\text { aOR (95\%Cl) }\end{array}$ \\
\hline \multicolumn{5}{|l|}{ Fixed effects } \\
\hline \multicolumn{5}{|l|}{ Level 1} \\
\hline \multicolumn{5}{|l|}{ Individual-level } \\
\hline Male (ref: female) & $1.41(0.85,2.34)$ & $2.38(1.19,4.78)^{*}$ & $2.28(1.09,4.74)^{*}$ & $2.50(1.06,5.89)^{*}$ \\
\hline Age $\geq 18$ (ref: $<18, y)$ & $1.15(0.69,1.93)$ & $0.33(0.12,0.92)^{*}$ & $0.37(0.14,1.03)$ & $0.30(0.09,0.94)^{*}$ \\
\hline \multicolumn{5}{|l|}{ Monthly income (ref: > 8000, THB) } \\
\hline$<5000$ & $0.87(0.58,1.33)$ & $0.75(0.42,1.36)$ & $0.71(0.40,1.27)$ & $0.70(0.37,1.32)$ \\
\hline $5000-8000$ & $1.11(0.72,1.74)$ & $0.99(0.60,1.63)$ & $0.95(0.57,1.59)$ & $0.93(0.53,1.64)$ \\
\hline Primary school or lower (ref: secondary school or above) & $1.47(1.04,2.07)^{*}$ & $1.49(1.13,1.96)^{* *}$ & $1.54(1.13,2.11)^{* *}$ & $1.54(1.05,2.28)^{*}$ \\
\hline Unemployed (ref: employed) & $1.11(0.73,1.67)$ & $2.39(1.28,4.49)^{* *}$ & $2.99(1.59,5.61)^{* *}$ & $3.22(1.67,6.21)^{* *}$ \\
\hline Drug-related crime history (ref: no) & $1.57(1.09,2.28)^{*}$ & $2.30(1.26,4.21)^{* *}$ & $2.18(1.15,4.11)^{*}$ & $2.35(1.16,4.74)^{*}$ \\
\hline Human rights violation (ref: no) & $1.17(0.68,2.03)$ & $1.42(0.68,2.93)$ & $1.32(0.65,2.71)$ & $1.43(0.70,2.93)$ \\
\hline \multicolumn{5}{|l|}{ Interpersonal-level } \\
\hline Family substance use (ref: no) & $1.60(1.14,2.26)^{* *}$ & & $2.23(1.64,3.02)^{* *}$ & $2.36(1.71,3.26)^{* *}$ \\
\hline Peer substance use (ref: no) & $2.15(1.51,3.08)^{* *}$ & & $1.67(1.07,2.61)^{*}$ & $1.63(1.02,2.61)^{*}$ \\
\hline \multicolumn{5}{|l|}{ Level 2} \\
\hline \multicolumn{5}{|l|}{ Neighborhood-level } \\
\hline Perception of neighborhood cohesion & $0.68(0.63,0.75)^{* *}$ & & & $0.85(0.76,0.95)^{* *}$ \\
\hline Perception of neighborhood crime & $1.32(1.26,1.38)^{* *}$ & & & $1.19(1.08,1.32)^{* *}$ \\
\hline Stigma surrounding addiction & $1.45(1.37,1.54)^{* *}$ & & & $1.25(1.14,1.38)^{* *}$ \\
\hline \multicolumn{5}{|l|}{ Random effects } \\
\hline Level $1^{1}$ & & 1.00 & 1.00 & 1.00 \\
\hline Level $2^{2}$ & & $4.55(1.51)^{* *}$ & $4.67(1.55)^{* *}$ & $1.92(0.78)^{* *}$ \\
\hline Median OR & & 7.65 & 7.85 & 3.75 \\
\hline IOR-80\% for neighborhood cohesion & & & & $(0.07,10.52)$ \\
\hline IOR-80\% for neighborhood crime & & & & $(0.10,14.73)$ \\
\hline IOR-80\% for stigma surrounding addiction & & & & $(0.10,15.44)$ \\
\hline
\end{tabular}

$\mathrm{OR}$, odds ratio; aOR, adjusted $\mathrm{OR}$; $\mathrm{Cl}$, confidence interval; ref, reference group; THB, Thai baht; IOR, interval OR.

$V$ ariance at level 1 was constrained to 1.

${ }^{2}$ Estimate standard error.

${ }^{*} p<0.05,{ }^{* *} p<0.01$.

the residents' health behavior because health-relevant information is shared and healthy behavior norms are adopted throughout the community [17]. Therefore, perceiving neighborhood cohesion may reflect greater information-sharing about the health effects and harmfulness of substance use, and cohesion could discourage drug use and help establish social norms opposed to substance use [31]. Another reason may be that methamphetamine is an illicit drug mainly used by drug users in Thailand. It is possible that the government's promotion of anti-drug social norms, including anti-methamphetamine campaigns, as well as steps taken to encourage community members to monitor residents involved in drug selling or drug use in their neighborhoods [32], support be- haviors incompatible with methamphetamine use. Nevertheless, our findings conflict with those of Byrnes et al. [23], Tucker et al. [33], and De Haan et al. [34] that perceived neighborhood cohesion was not significantly associated with adolescent substance use. This inconsistency may be due to differences in the study population, neighborhood cohesion measures, and/or data analysis techniques; of particular note, this study used aggregate-level assessments of neighborhood cohesion and a multilevel analysis with a nested data structure.

In term of perceived neighborhood crime, we found that residents who perceived their neighborhood to have more crime had a higher likelihood of both MET-AMP and OID with MET-AMP. Our results are consistent with previous studies, 
Table 3. ORs and $95 \%$ Cls from the multilevel multinomial logistic regression for other illicit drug use with methamphetamine pills

\begin{tabular}{|c|c|c|c|c|}
\hline & $\begin{array}{l}\text { Bivariate } \\
\text { OR (95\% CI) }\end{array}$ & $\begin{array}{c}\text { Model } 1 \\
\text { aOR (95\% CI) }\end{array}$ & $\begin{array}{c}\text { Model } 2 \\
\text { aOR (95\% CI) }\end{array}$ & $\begin{array}{c}\text { Model } 3 \\
\text { aOR (95\% CI) }\end{array}$ \\
\hline \multicolumn{5}{|l|}{ Fixed effects } \\
\hline \multicolumn{5}{|l|}{ Level 1} \\
\hline \multicolumn{5}{|l|}{ Individual-level } \\
\hline Male (ref: female) & $0.59(0.36,0.98)$ & $0.65(0.41,1.03)$ & $0.62(0.38,0.98)^{*}$ & $0.69(0.39,1.24)$ \\
\hline Age $\geq 18($ ref: $<18, y)$ & $0.57(0.34,0.97)^{*}$ & $0.31(0.15,0.59)^{* *}$ & $0.33(0.17,0.63)^{* *}$ & $0.27(0.13,0.55)^{*}$ \\
\hline \multicolumn{5}{|l|}{ Monthly income (ref: > 8000, THB) } \\
\hline$<5000$ & $1.08(0.69,1.69)$ & $0.74(0.42,1.32)$ & $0.72(0.42,1.27)$ & $0.72(0.39,1.29)$ \\
\hline $5000-8000$ & $1.05(0.64,1.71)$ & $0.95(0.51,1.08)$ & $0.89(0.46,1.73)$ & $0.88(0.44,1.74)$ \\
\hline Primary school or lower (ref: secondary school or above) & $1.48(1.02,2.14)^{*}$ & $1.55(1.09,2.19)^{*}$ & $1.56(1.06,2.29)^{*}$ & $1.57(1.01,2.45)^{*}$ \\
\hline Unemployed (ref: employed) & $1.45(0.95,2.25)$ & $2.08(1.16,3.74)^{*}$ & $2.42(1.32,4.42)^{* *}$ & $2.63(1.40,4.94)^{* *}$ \\
\hline Drug-related crime history (ref: no) & $1.67(1.12,2.50)^{*}$ & $3.71(1.47,9.33)^{* *}$ & $3.52(1.37,9.03)^{* *}$ & $3.71(1.43,9.62)^{* *}$ \\
\hline Human rights violation (ref: no) & $1.37(0.77,2.44)$ & $1.94(0.89,4.22)$ & $1.93(0.90,4.09)$ & $2.03(0.96,4.28)$ \\
\hline \multicolumn{5}{|l|}{ Interpersonal-level } \\
\hline Family substance use (ref: no) & $1.24(0.85,1.79)$ & & $1.39(1.02,1.89)^{*}$ & $1.47(1.07,2.02)^{*}$ \\
\hline Peer substance use (ref: no) & $1.87(1.28,2.76)^{* *}$ & & $1.75(1.09,2.78)^{*}$ & $1.69(1.09,2.63)^{*}$ \\
\hline \multicolumn{5}{|l|}{ Level 2} \\
\hline \multicolumn{5}{|l|}{ Neighborhood-level } \\
\hline Perception of neighborhood cohesion & $0.75(0.68,0.82)^{* *}$ & & & $0.89(0.81,0.97)^{*}$ \\
\hline Perception of neighborhood crime & $1.19(1.15,1.24)^{* *}$ & & & $1.14(1.06,1.22)^{* *}$ \\
\hline Stigma surrounding addiction & $1.26(1.19,1.34)^{* *}$ & & & $1.12(1.06,1.19)^{* *}$ \\
\hline \multicolumn{5}{|l|}{ Random effects } \\
\hline Level $1^{1}$ & & 1.00 & 1.00 & 1.00 \\
\hline Level $2^{2}$ & & $1.25(0.47)^{* *}$ & $1.23(0.47)^{* *}$ & $0.22(0.17)^{*}$ \\
\hline Median OR & & 2.91 & 2.88 & 1.56 \\
\hline IOR-80\% for neighborhood cohesion & & & & $(0.38,2.08)$ \\
\hline IOR-80\% for neighborhood crime & & & & $(0.48,2.66)$ \\
\hline IOR-80\% for stigma surrounding addiction & & & & $(0.47,2.63)$ \\
\hline
\end{tabular}

$\mathrm{OR}$, odds ratio; $\mathrm{aOR}$, adjusted $\mathrm{OR}$; $\mathrm{Cl}$, confidence interval; $\mathrm{THB}$, Thai baht; ref, reference group; IOR, interval OR.

'Variance at level 1 was constrained to 1.

${ }^{2}$ Estimate standard error.

${ }^{*} p<0.05,{ }^{* *} p<0.01$.

such as Shareck and Ellaway [15] and Theall et al. [16], and several articles have found that residing in a neighborhood environment with prevalent illicit drug use and dealing, as well as high crime rates and high levels of perceived crime, is unsafe and stressful. Substance use may then emerge as a coping mechanism to counter the stressful environment $[15,19,20]$. Our findings are inconsistent with those of Yabiku et al. [35] and Kepple and Freisthler [36], potentially due to differences in the study population and neighborhood measurements [37]. Regarding the stigma surrounding addiction, living in neighborhoods with a high perceived stigma surrounding addiction was found to make drug use more likely $[9,21]$. An ex- planation for this is that the community expresses negative attitudes toward drug users and labels them as bad, weak, immoral, dangerous, and unreliable, which produces negative effects, such as social alienation, human rights abuses, and a risk of drug use [21,38].

Covariates such as age, educational level, occupational status, drug-related crime history, and peer and family drug use were related to both MET-AMP and OID with MET-AMP. This finding is consistent with those of Rodriguez et al. [6], Tomori et al. [9], Mennis et al. [19], and Silins et al. [25]. Young age, a low educational level, and unemployment were significantly associated with drug use. Regarding drug-related crime histo- 
ry, it is possible that PWUD with a history of drug offenses were more likely to use drugs, because they may have learned how to use new drugs and shared drug experiences with other offenders [39]. Moreover, drug use was associated with family and peer networks involved in drug activity; in particular, parents who use substances might be negative behavior models and may provide adolescents with access to drugs, thereby increasing the likelihood of their adolescents' substance use $[14,33,40]$. A study in Thailand showed that after being released from CDDCs, some detainees continued to experience drug cravings and returned to drug use in contexts in which their family members still used drugs and shared drugs with them [39].

The study had a cross-sectional design and therefore cannot establish a temporal relationship or causality. Some bias may have been present, although residents' perceptions of their neighborhood environments have been shown to be stronger than objective assessments in terms of relationships to health by Hadley-Ives et al. [37]. Finally, we assessed perceived neighborhood environments and substance use in the 3 months prior to detention, and the retrospective nature of the questions may have introduced recall bias. Despite these limitations, this study has the strengths of controlling for a wide range of covariates, including a large sample size, and utilizing a nationally representative sample, enabling our findings to be generalized. This study not only provided further insights into neighborhood-level risk factors and protective factors regarding substance use among hard-to-reach groups, but also revealed important descriptive findings, because to the best of our knowledge, no other study has investigated the effects of the neighborhood environment among drug addicts on a nationwide scale. Nonetheless, further studies with a longitudinal design are required. We also suggest that multi-level interventions should be implemented in disorganized neighborhoods to reduce substance use among drug users and to diminish the tendency of users to cycle between these neighborhoods and CDDCs.

In conclusion, this study demonstrated that 3 neighborhood-level environmental factors were associated with substance use in the Thai setting. Greater perceived neighborhood cohesion was a protective factor, whereas greater perceived neighborhood crime and stigma surrounding addiction were risk factors for substance use. These results imply that neighborhood-level and local socioeconomic factors should be considered when developing preventive interventions for substance use reduction. The application of these results might be suggested that neighborhood-level and local socioeconomic factors can applied by judgement considered while developing interventions for substance use protection measured.

\section{ACKNOWLEDGEMENTS}

This study used data from a portion of a PhD dissertation. The authors gratefully acknowledge the Thai Health Promotion Foundation for providing funding support for this research. We would like to thank all study subjects for participation and all CDDCs for their support in data collection.

\section{CONFLICT OF INTEREST}

The authors have no conflicts of interest associated with the material presented in this paper.

\section{ORCID}

Suneerat Yangyuen http://orcid.org/0000-0002-6023-1201

Manop Kanato http://orcid.org/0000-0001-8607-3400

Udomsak Mahaweerawat http://orcid.org/0000-0003-35127936

\section{REFERENCES}

1. United Nations Office on Drugs and Crime. World drug report 2016 [cited 2016 Nov 23]. Available from: https://www.unodc. org/wdr2016/.

2. Werb D, Kamarulzaman A, Meacham MC, Rafful C, Fischer B, Strathdee SA, et al. The effectiveness of compulsory drug treatment: a systematic review. Int J Drug Policy 2016;28:1-9.

3. Kamarulzaman A, McBrayer JL. Compulsory drug detention centers in East and Southeast Asia. Int J Drug Policy 2015;26 Suppl 1:S33-537.

4. Thai Office of the Council of State. Narcotic Addict Rehabilitation Act 2002 [cited 2015 Dec 20]. Available from: http://web. krisdika.go.th/data/law/law2/\%bf01/\%bf01-20-2545-a0001. pdf (Thai).

5. Department of Probation. Statistics of drug offenders in Thailand [cited 2015 Jan 10]. Available from: http://164.115.41.115/ doc_dop/file/categories2/20180110023613-0026101014.pdf (Thai). 
6. Rodriguez N, Katz C, Webb VJ, Schaefer DR. Examining the impact of individual, community, and market factors on methamphetamine use: a tale of two cities. J Drug Issues 2005; 35(4):665-693.

7. Kunarak K. The development of a recidivism prevention on drug users model: a case study of the juvenile observation and protection department [dissertation]. Bangkok: Silpakorn University; 2012 (Thai).

8. Rogers JD, Ramaswamy M, Cheng Cl, Richter K, Kelly PJ. Perceptions of neighborhood social environment and drug dependence among incarcerated women and men: a cross-sectional analysis. Subst Abuse Treat Prev Policy 2012;7(1):39.

9. Tomori C, Go VF, Tuan le N, Huong NM, Binh NT, Zelaya CE, et al. "In their perception we are addicts": social vulnerabilities and sources of support for men released from drug treatment centers in Vietnam. Int J Drug Policy 2014;25(5):897-904.

10. Thomson N. Detention as treatment: detention of methamphetamine users in Cambodia, Laos, and Thailand; 2010 [cited 2017 Dec 30]. Available from: https://www.opensocietyfoundations.org/sites/default/files/Detention-as-Treatment- 20100301. pdf.

11. Kallanasute $K$, Surapat A, Kaewseengam J. The evaluation of rehabilitation of offenders in communities. Bangkok: Department of Probation, Ministry of Justice; 2010, p. 57 (Thai).

12. Galea S, Nandi A, Vlahov D. The social epidemiology of substance use. Epidemiol Rev 2004;26(1):36-52.

13. Duncan SC, Duncan TE, Strycker LA. A multilevel analysis of neighborhood context and youth alcohol and drug problems. Prev Sci 2002;3(2):125-133.

14. Embry D, Hankins M, Biglan A, Boles S. Behavioral and social correlates of methamphetamine use in a population-based sample of early and later adolescents. Addict Behav 2009; 34(4):343-351.

15. Shareck M, Ellaway A. Neighbourhood crime and smoking: the role of objective and perceived crime measures. BMC Public Health 2011;11:930.

16. Theall KP, Sterk CE, Elifson KW. Perceived neighborhood fear and drug use among young adults. Am J Health Behav 2009; 33(4):353-365.

17. Patterson JM, Eberly LE, Ding Y, Hargreaves M. Associations of smoking prevalence with individual and area level social cohesion. J Epidemiol Community Health 2004;58(8):692-697.

18. Sampson RJ, Raudenbush SW, Earls F. Neighborhoods and violent crime: a multilevel study of collective efficacy. Science 1997;277(5328):918-924.
19. Mennis J, Stahler GJ, Mason MJ. Risky substance use environments and addiction: a new frontier for environmental justice research. Int J Environ Res Public Health 2016;13(6):607.

20. Boardman JD, Finch BK, Ellison CG, Williams DR, Jackson JS. Neighborhood disadvantage, stress, and drug use among adults. J Health Soc Behav 2001;42(2):151-165.

21. Livingston JD, Milne T, Fang ML, Amari E. The effectiveness of interventions for reducing stigma related to substance use disorders: a systematic review. Addiction 2012;107(1):39-50.

22. Cheng Y, Sherman SG, Srirat N, Vongchak T, Kawichai S, Jittiwutikarn J, et al. Risk factors associated with injection initiation among drug users in Northern Thailand. Harm Reduct J 2006:3:10.

23. Byrnes HF, Miller BA, Chamratrithirong A, Rhucharoenpornpanich O, Cupp PK, Atwood KA, et al. The roles of perceived neighborhood disorganization, social cohesion, and social control in urban Thai adolescents' substance use and delinquency. Youth Soc 2013;45(3):404-427.

24. Bronfenbrenner U. Ecological models of human development. Int Encycl Educ 1994;3(2):1643-1647.

25. Silins E, Fergusson DM, Patton GC, Horwood LJ, Olsson CA, Hutchinson DM, et al. Adolescent substance use and educational attainment: an integrative data analysis comparing cannabis and alcohol from three Australasian cohorts. Drug Alcohol Depend 2015;156:90-96.

26. Buckner JC. The development of an instrument to measure neighborhood cohesion. Am J Community Psychol 1988; 16(6):771-791.

27. Rosenberg D, Ding D, Sallis JF, Kerr J, Norman GJ, Durant N, et al. Neighborhood Environment Walkability Scale for Youth (NEWS-Y): reliability and relationship with physical activity. Prev Med 2009;49(2-3):213-218.

28. Martinez SM, Blanco E, Delva J, Burrows R, Reyes M, Lozoff B, et al. Perception of neighborhood crime and drugs increases cardiometabolic risk in Chilean adolescents. J Adolesc Health 2014;54(6):718-723.

29. Kanato M, Leyatikul P. Thai addiction stigma scale. Community Health Dev 2014; 2(2):1-18 (Thai).

30. Lin EY, Witten K, Casswell S, You RQ. Neighbourhood matters: perceptions of neighbourhood cohesiveness and associations with alcohol, cannabis and tobacco use. Drug Alcohol Rev 2012;31(4):402-412.

31. Ahern J, Galea S, Hubbard A, Syme SL. Neighborhood smoking norms modify the relation between collective efficacy and smoking behavior. Drug Alcohol Depend 2009;100(1- 
2):138-145.

32. Office of the Narcotics Control Board. Drug abuse prevention and solving action plan in 2015-2019 [cited 2015 Dec 1]. Available from: https://www.opdc.go.th/uploads/files/2558/att1203.2 v19_58_1.pdf(Thai).

33. Tucker JS, Pollard MS, de la Haye K, Kennedy DP, Green HD Jr. Neighborhood characteristics and the initiation of marijuana use and binge drinking. Drug Alcohol Depend 2013;128(1-2) :83-89.

34. De Haan L, Boljevac T, Schaefer K. Rural community characteristics, economic hardship, and peer and parental influences in early adolescent alcohol use. J Early Adolesc 2009;30(5):629650.

35. Yabiku ST, Dixon Rayle A, Okamoto SK, Marsiglia FF, Kulis S. The effect of neighborhood context on the drug use of American Indian youth of the Southwest. J Ethn Subst Abuse 2007; 6(2):181-204.

36. Kepple NJ, Freisthler B. Exploring the ecological association between crime and medical marijuana dispensaries. J Stud Alcohol Drugs 2012;73(4):523-530.

37. Hadley-Ives E, Stiffman AR, Elze D, Johnson S. D, Dore P. Measuring neighborhood and school environments perceptual and aggregate approaches. J Hum Behav Soc Environ 2000;3(1):1-28.

38. Luo T, Wang J, Li Y, Wang X, Tan L, Deng Q, et al. Stigmatization of people with drug dependence in China: a communitybased study in Hunan province. Drug Alcohol Depend 2014;134:285-289.

39. Kanato $M$, Yangyuen $S$. Situation and outcome of drugs treatment in compulsory drug treatment system in Thailand: case study of hospitals under department of medical services. Khon Kaen: Khon Kaen University; 2017, p. 121 (Thai).

40. Foo YC, Tam CL, Lee TH. Family factors and peer influence in drug abuse: a study in rehabilitation centre. Int J Collab Res Intern Med Public Health 2012;4(3):190-201. 